\title{
Mechanistic Investigation of Palladium-Catalyzed Allylic C-H Activation
}

\author{
Engelin, Casper Junker; Jensen, Thomas; Rodríguez-Rodríguez, Sergio; Fristrup, Peter
}

Published in:

A C S Catalysis

Link to article, DOI:

$10.1021 / \operatorname{cs} 3007878$

Publication date:

2013

Document Version

Publisher's PDF, also known as Version of record

Link back to DTU Orbit

Citation (APA):

Engelin, C. J., Jensen, T., Rodríguez-Rodríguez, S., \& Fristrup, P. (2013). Mechanistic Investigation of

Palladium-Catalyzed Allylic C-H Activation. A C S Catalysis, 3, 294-302. https://doi.org/10.1021/cs3007878

\section{General rights}

Copyright and moral rights for the publications made accessible in the public portal are retained by the authors and/or other copyright owners and it is a condition of accessing publications that users recognise and abide by the legal requirements associated with these rights.

- Users may download and print one copy of any publication from the public portal for the purpose of private study or research.

- You may not further distribute the material or use it for any profit-making activity or commercial gain

- You may freely distribute the URL identifying the publication in the public portal 


\title{
Mechanistic Investigation of Palladium-Catalyzed Allylic $\mathrm{C}-\mathrm{H}$ Activation
}

\author{
Casper Engelin, Thomas Jensen, ${ }^{\dagger}$ Sergio Rodriguez-Rodriguez, ${ }^{\ddagger}$ and Peter Fristrup* \\ Department of Chemistry, Technical University of Denmark, Building 201 Kemitorvet, DK- 2800 Kongens Lyngby, Denmark
}

\author{
Supporting Information
}

ABSTRACT: The mechanism for the palladium-catalyzed allylic $\mathrm{C}-\mathrm{H}$ activation was investigated using a combination of experimental and theoretical methods. A Hammett study revealed a buildup of a partial negative charge in the ratedetermining step, and determination of the kinetic isotope effect (KIE) indicated that the $\mathrm{C}-\mathrm{H}$ bond is broken in the turnover-limiting transition state. These experimental findings

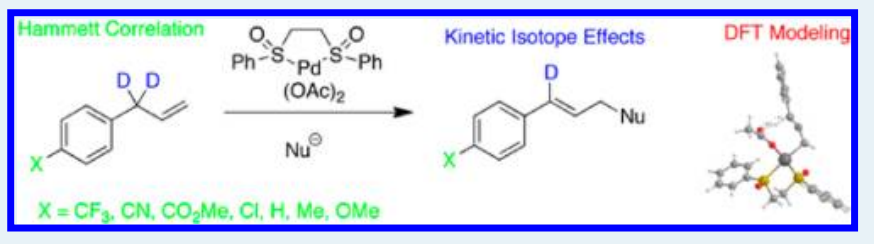
were further substantiated by carrying out a detailed density functional theory (DFT)-based investigation of the entire catalytic cycle. The DFT modeling supports a mechanism in which a coordinated acetate acts as a base in an intramolecular fashion during the $\mathrm{C}-\mathrm{H}$ activation step. The reoxidation of palladium was found to reach an energy level similar to that of the $\mathrm{C}-\mathrm{H}$ activation. Calculations of turnover frequencies for the entire catalytic cycle for the $\mathrm{C}-\mathrm{H}$ alkylation were used to acquire a better understanding of the experimental KIE value. The good correspondence between the experimental KIE and the computed KIE values allows discrimination between scenarios where the acetate is acting in an intramolecular fashion $(\mathrm{C}-\mathrm{H}$ alkylation) and an intermolecular fashion ( $\mathrm{C}-\mathrm{H}$ acetoxylation and $\mathrm{C}-\mathrm{H}$ amination).

KEYWORDS: $\mathrm{C}-\mathrm{H}$ activation, allylic alkylation, catalysis, palladium, mechanism, kinetic isotope effect

\section{INTRODUCTION}

Although synthetic chemists have shown that practically any molecule can be synthesized given the appropriate amount of resources, ${ }^{1}$ there is still considerable progress to be made in terms of synthetic efficiency. Many popular synthetic methodologies are still undesirable from a green and sustainable chemistry perspective because they often employ hazardous or even toxic reagents and often result in stoichiometric amounts of byproducts. In recent years, $\mathrm{C}-\mathrm{H}$ activation has emerged as a powerful and popular strategy for improving synthetic efficiency by imparting chemical reactivity on otherwise unreactive $\mathrm{C}-\mathrm{H}$ bonds. ${ }^{2}$ Especially $\mathrm{C}-\mathrm{H}$ activation reactions catalyzed by $\mathrm{Pd}$ has seen some significant development. ${ }^{3} \mathrm{An}$ example of the recent development is the allylic $\mathrm{C}-\mathrm{H}$ alkylation disclosed by White and Shi independently, ${ }^{4,5}$ in which the need for a classical leaving group (e.g., acetate, carbonate) is circumvented through $\mathrm{C}-\mathrm{H}$ activation of a benzylic proton. ${ }^{6}$ The stoichiometric activation of nonfunctionalized alkenes was first achieved by Trost and Fullerton in $1973,{ }^{7}$ but the lack of a catalytic version hampered the widespread use of this methodology. Attention was therefore focused on the further development of the catalytic protocol now known as the Tsuji-Trost allylation, which utilizes preoxidized substrates, for example, allyl acetates.

It was found by White and Shi that a full catalytic cycle of allylic $\mathrm{C}-\mathrm{H}$ activation followed by functionalization could be achieved by adding stoichiometric amounts of oxidant, thereby producing the desired cross-coupling product in a manner similar to the classical Tsuji-Trost allylation, as shown in Scheme 1 . However, the reaction has not yet gained the same
Scheme 1. Proposed Catalytic Cycle for Allylic C-H Alkylation, Consisting of Precoordination, C-H Activation, Nucleophilic Attack, and Reoxidation

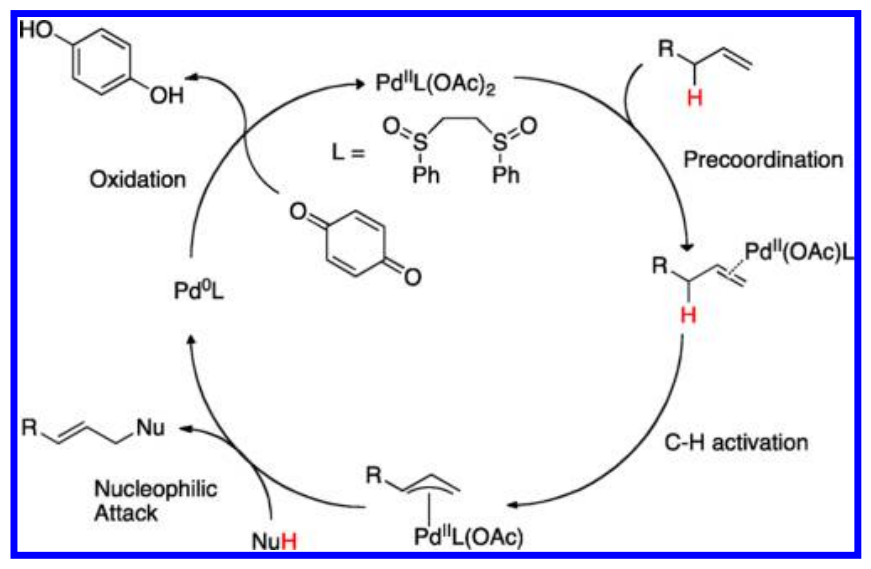

level of sophistication as the Tsuji-Trost allylation in which a wide range of nucleophiles are tolerated. Furthermore, the reaction outcome of the Tsuji-Trost allylation can often be rendered chiral by use of a suitable chiral, nonracemic ligand on palladium. Some progress has been made in introducing chirality in the allylic $\mathrm{C}-\mathrm{H}$ activation. ${ }^{8}$

To allow for the further rational development of this transformation, we decided to carry out a detailed mechanistic

Received: December 5, 2012 
investigation of the Pd-catalyzed allylic $\mathrm{C}-\mathrm{H}$ alkylation with focus on the crucial $\mathrm{C}-\mathrm{H}$ activation. In line with earlier work, we have selected to utilize both experimental and computational methods, ${ }^{9}$ which is emerging as a powerful combination in current physical organic chemistry. More specifically, we have carried out a Hammett study employing a series of parasubstituted allylbenzenes using competition experiments. By monitoring competition experiments between allylbenzene and various para-substituted allylbenzenes, it was possible to determine the relative reactivities. Furthermore, we have synthesized a deuterated substrate, which has allowed us to determine the kinetic isotope effect (KIE) under conditions relevant for catalysis. As in earlier studies, we have complemented the experimental investigations with a theoretical study employing density functional theory (DFT).

\section{EXPERIMENTAL STUDY}

The mechanistic study includes Hammett studies, in line with earlier work, ${ }^{10}$ in which the observed relative reactivity of different para-substituted allylbenzenes is used to characterize the rate-determining step. This method can also be used to differentiate between various reaction pathways on the basis of the quality of the fit against different sets of $\sigma$ values (e.g., "normal", "cationic", "radical", or "anionic"), which then serves as a starting point for a computational investigation of the reaction. $^{9}$

In the current study, we have selected a set of parasubstituted allylbenzenes for competitive alkylation experiments. The allylbenzene substrates were tested in noncompetitive alkylation reactions using the standard conditions reported by White, and the alkylated products were obtained with yields and selectivities comparable to the results reported by White and co-workers. ${ }^{4} \mathrm{We}$ envisioned that their relative reactivity could be determined by means of a series of competition experiments. ${ }^{11,12}$ In these experiments, two substrates were alkylated simultaneously, and the relative disappearance of the starting material could be quantified by gas chromatography (GC) using an internal standard (Scheme 2).

Scheme 2. Competition Studies for the Allylic C-H Alkylation of Allylbenzene versus Para-Substituted Allylbenzene Derivatives ${ }^{a}$

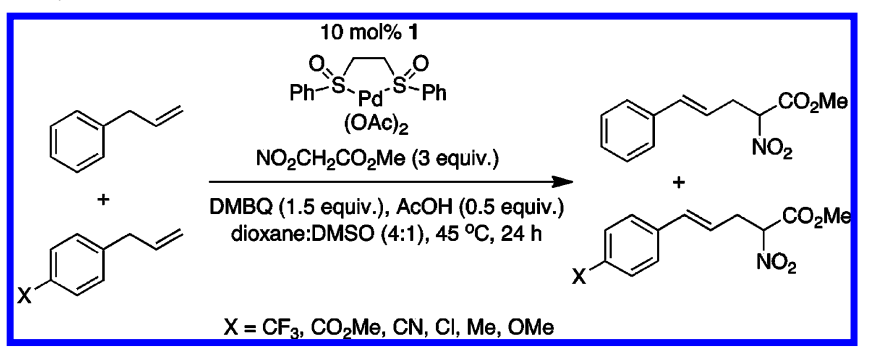

${ }^{a} \mathrm{DBMQ}=$ dimethyl benzoquinone.

Six different para-substituted allylbenzenes, of which five had been reported by White and co-workers to give $50-65 \%$ yield, $E: Z$ isomer ratios of $>20: 1$, and linear/branched ratios ranging from $1.7: 1$ to $12: 1$, were included in this study. ${ }^{13}$ Samples were taken at the beginning of the reaction and at regular intervals, and GC quantified the disappearance of both allylbenzene itself and the para-substituted allylbenzene. Assuming that the two substrates follow the same mechanism, the reaction order in each component will be the same for both substrates in the competition experiment. If the reaction is first-order with respect to the substrate, the relative reactivity can be obtained as the slope of the line when $\ln \left(c_{x} / c_{x, 0}\right)$ for one substrate is plotted against $\ln \left(c_{\mathrm{H}} / \mathcal{c}_{\mathrm{H}, 0}\right)$ for allylbenzene. As can be seen in Figure 1, the good linear fits validate the reaction order assumptions.

The data from the competition experiments resulted in six straight lines, all with $R^{2}$ values above 0.99 (Figure 1). With the relative reactivities in hand, the Hammett plot could now be constructed using $\sigma$ values from the literature (Figure 2). ${ }^{14}$ The slope of the line was positive, indicating that the reaction is accelerated by electron-withdrawing substituents in the para position of the allylbenzene substrates. The observed relative reactivities were in accordance with the "anionic" $\sigma$ values (see the Supporting Information for correlations to other $\sigma$ values), thus eliminating the possibility of the $\mathrm{C}-\mathrm{H}$ activation being a hydride abstraction by the Pd catalyst, which would be expected to leave a partial positive charge on the remaining allyl fragment.

Instead, the positive slope $(\rho=0.37)$ shows that a negative charge is built up in the transition state (TS) of the ratedetermining step. This indicates that the $\mathrm{C}-\mathrm{H}$ activation takes place through the abstraction of an allylic proton. To further support this interpretation, a deuterium kinetic isotope effect measurement was undertaken in line with earlier work. ${ }^{15}$

\section{DEUTERIUM KINETIC ISOTOPE EFFECT}

To determine the KIE, $d_{2}$-allylbenzene (2) was synthesized. The kinetic isotope effect was determined for three $\mathrm{C}-\mathrm{H}$ activation reactions reported ${ }^{16}$ with catalyst 1 : the allylic $\mathrm{C}-\mathrm{H}$ alkylation (a), ${ }^{4}$ allylic C-H acetoxylation (b) ${ }^{17}$ and allylic C$\mathrm{H}$ amination (c) ${ }^{18}$ (Scheme 3 ). The proposed catalytic cycle for the palladium-catalyzed allylic $\mathrm{C}-\mathrm{H}$ amination is similar to the allylic $\mathrm{C}-\mathrm{H}$ alkylation, the only difference being the use of different nucleophiles, and a similar mechanism can also be proposed for the $\mathrm{C}-\mathrm{H}$ acetoxylation. It was investigated if the $\mathrm{C}-\mathrm{H}$ activation step was also the rate-determining step of the catalytic cycles for these two related transformations. The obtained KIE values were compared with calculated values for possible proton abstraction mechanisms in the computational study.

In the allylic $\mathrm{C}-\mathrm{H}$ alkylation (Scheme 3, a), a deuterium isotope effect $k_{\mathrm{H}} / k_{\mathrm{D}}$ of $5.5( \pm 0.07)$ was determined (for further details, see the Supporting Information). A KIE of this magnitude indicates that the $\mathrm{C}-\mathrm{H}$ bond is broken in the selectivity-determining step. Furthermore, such a pronounced $\mathrm{KIE}$ is compatible with mechanisms in which $\mathrm{C}-\mathrm{H}$ bond cleavage is occurring simultaneously with carbon-palladium bond formation. ${ }^{19}$ For the allylic $\mathrm{C}-\mathrm{H}$ acetoxylation (Scheme 3 , b), a slightly lower KIE of 4.5 was determined, supporting the theory of the $\mathrm{C}-\mathrm{H}$ activation step being the ratedetermining step also in this variant of the methodology. Finally, a KIE value of 4.7 was determined for the allylic $\mathrm{C}-\mathrm{H}$ amination (Scheme 3, c).

Furthermore, the KIE was also determined by two allylic C$\mathrm{H}$ alkylation reactions run in parallel: one with allylbenzene and the other with 2 . Hartwig recently pointed out the importance of this reaction setup for further elucidating the KIE value. ${ }^{20}$ These experiments gave a KIE of $2.6( \pm 0.2)$, which implies that another step in the catalytic cycle has a TS that is of similar energy as the $\mathrm{C}-\mathrm{H}$ activation TS (for further details, see the Supporting Information). The former KIE of 5.5 represents the 


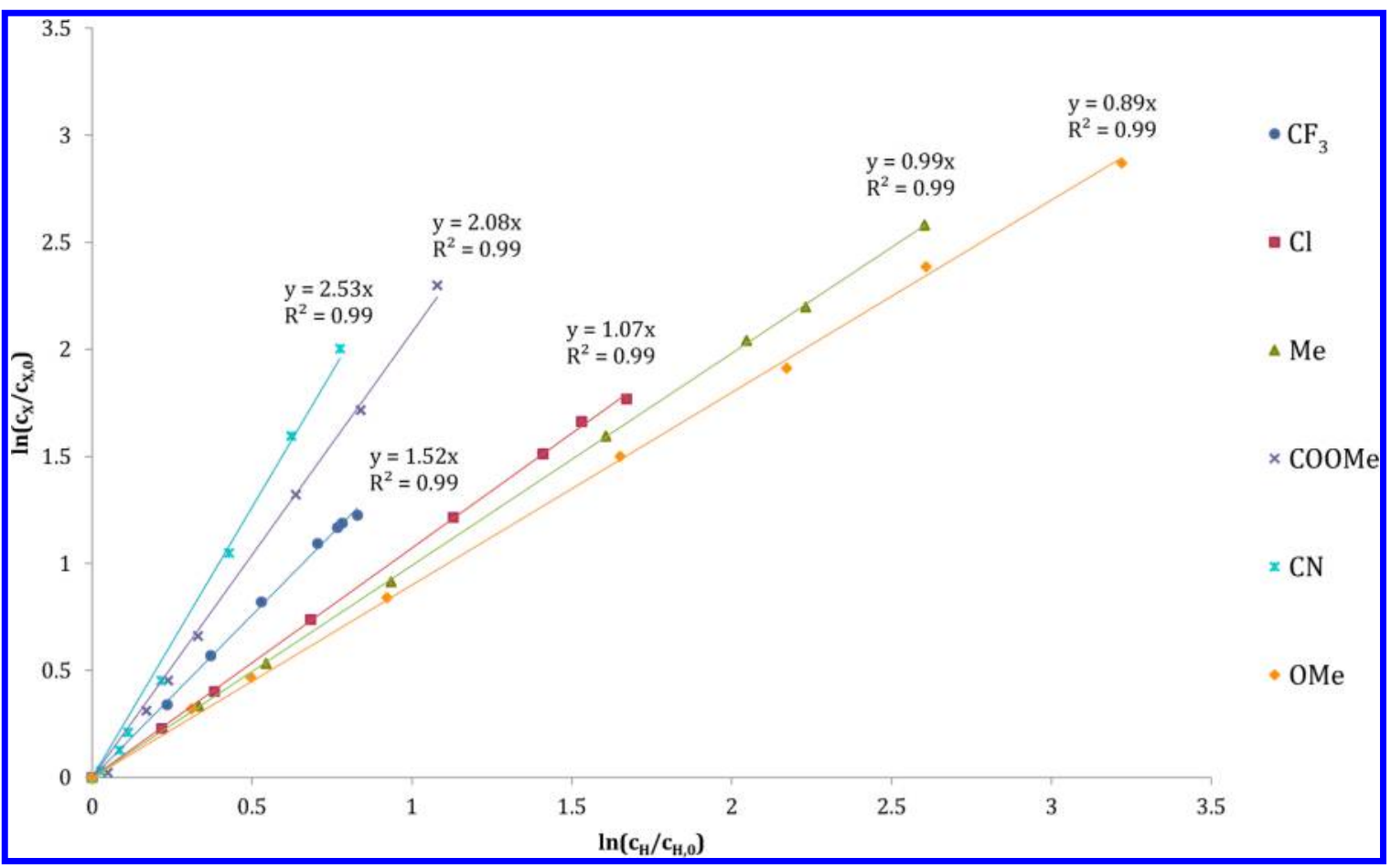

Figure 1. Kinetic data obtained in the alkylation of para-substituted allylbenzenes where the slopes correspond to the reactivity relative to the parent allylbenzene.

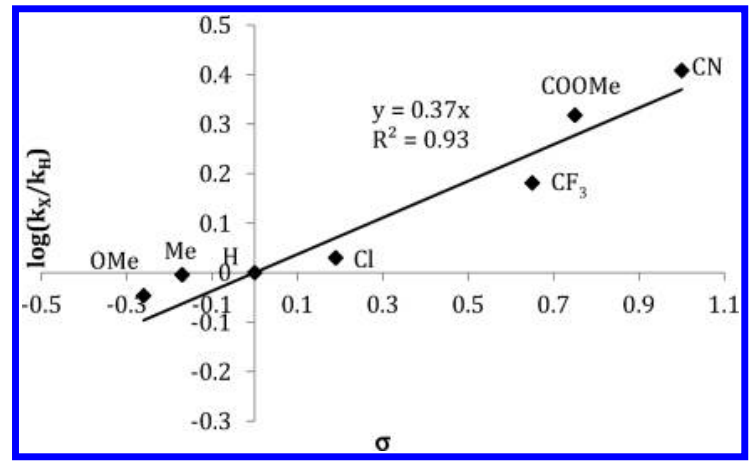

Figure 2. Hammett plot for the alkylation of para-substituted allylbenzenes.

difference in reactivity between the two substrates in the elementary step in which the $\mathrm{C}-\mathrm{H}$ bond is broken, and the KIE of 2.6 is the difference in reactivity when including the full catalytic cycle. Since this latter value is lower, it clearly indicates that a second step in the catalytic cycle also have an important influence on the observed overall reaction rate. We interpret these data as a confirmation of the existence of a second step in the catalytic cycle, with a barrier similar to that of the $\mathrm{C}-\mathrm{H}$ activation.

It was also investigated if deuterium scrambling occurred in the three $\mathrm{C}-\mathrm{H}$ activation reactions, since this would indicate whether the $\mathrm{C}-\mathrm{H}$ activation step is irreversible. Performing a comparative allylic $\mathrm{C}-\mathrm{H}$ alkylation experiment between 2 and 4-allyltoluene showed no deuterium scrambling between the allylic substrates and no loss of incorporated deuterium in the linear product (see the Supporting Information). Since no deuterium scrambling is observed, the $\mathrm{C}-\mathrm{H}$ activation step is irreversible under the experimental conditions employed in these reactions. Both the allylic $\mathrm{C}-\mathrm{H}$ amination and the allylic $\mathrm{C}-\mathrm{H}$ acetoxylation were then carried out using 2 and 4-
Scheme 3. The Reactions for Determination of the KIE for the Palladium-Catalyzed Allylic $\mathrm{C}-\mathrm{H}$ Alkylation, Allylic C$\mathrm{H}$ Acetoxylation, and Allylic $\mathrm{C}-\mathrm{H}$ Amination ${ }^{a}$

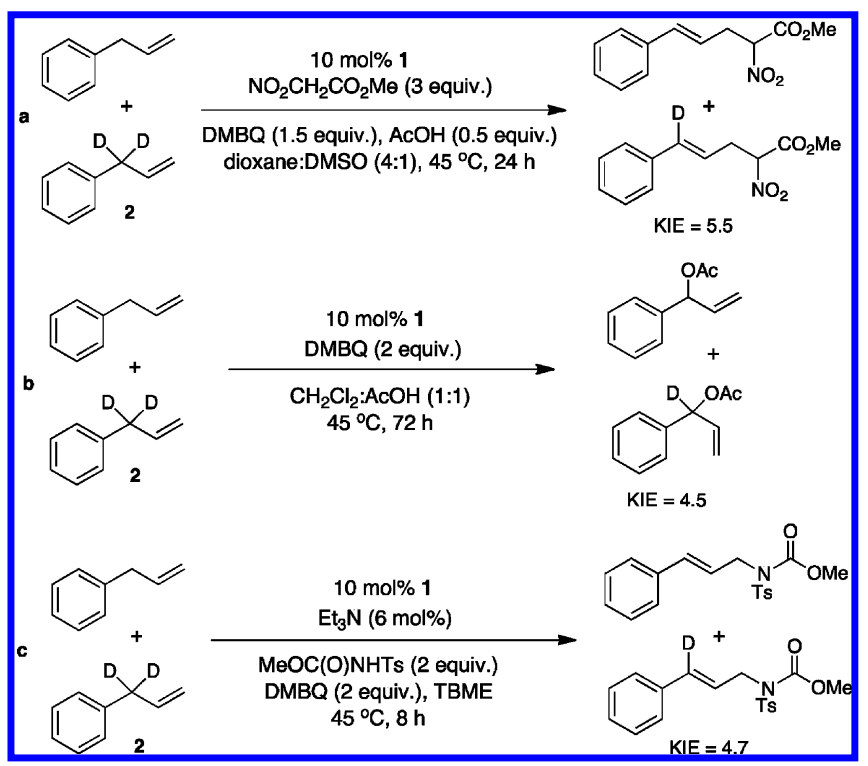

${ }^{a_{T B M E}}=$ tert-butyl methyl ether.

allyltoluene to check for deuterium scrambling, but no scrambling was observed.

Performing the $\mathrm{C}-\mathrm{H}$ activation on the deuterated substrate with stoichiometric amounts of $\mathbf{1}$ to form the bis[chloro(1,2,3trihapto-allylbenzene- $d_{1}$ )palladium(II)] complex, using the procedure with $n$ - $\mathrm{Bu}_{4} \mathrm{NCl}$ reported by White and co-workers for the synthesis of the nondeuterated Pd complex, ${ }^{4}$ proceeded smoothly and gave $61 \%$ yield after $5 \mathrm{~h}$. NMR spectroscopy was used to verify that the complex had full deuterium content in the allylic position, as shown in Figure 3, which is in accordance 
with a C-D activation without isomerization (see the Supporting Information).

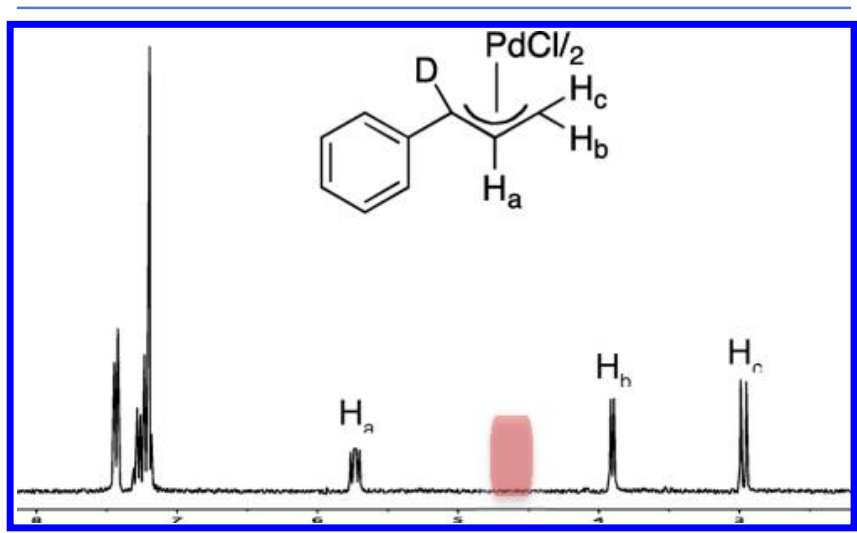

Figure 3. ${ }^{1} \mathrm{H}$ NMR spectrum of the bis[chloro(1,2,3-trihaptoallylbenzene- $d_{1}$ )palladium(II)] complex. Red marker highlights the chemical shift of a benzylic proton at $4.62 \mathrm{ppm}^{4}$

\section{COMPUTATIONAL STUDY}

To gain further insight into the mechanism behind the allylic $\mathrm{C}-\mathrm{H}$ activation, a computational study was carried out. This was performed with DFT employing the B3LYP functional with added dispersion interactions calculated using Grimme's D3 correction. ${ }^{21}$ All structures, intermediates, and transition states were also determined with the M06 functional, since this functional is known to account for dispersion interactions efficiently in organometallic systems. ${ }^{22}$ Since the M06 functional gave similar trends and approximately the same energy barriers as B3LYP-D3 in these investigations, the focus will be only on results calculated using B3LYP-D3. The basis set chosen for the study was LACVP* as incorporated in Jaguar v. 7.9, which entails an effective core potential (ECP) and basis set for palladium and a $6-31 G^{*}$ basis set for other atoms. The calculations were performed on the full substrate and ligand used in the experiments to allow a comparison between experiment and theory, which entailed using allylbenzene as the substrate. ${ }^{23,24}$ The ligand has a meso or a chiral racemic form, and for the calculations, the catalyst complex with the lowest energy was utilized, which was the complex with the chiral ligand. $^{25}$

On the basis of the proposed mechanism in Scheme 1, the first step is the coordination of the allylbenzene substrate to the catalyst. As expected when optimizing the structure of the precatalyst $\mathbf{1}$, the preferred square planar geometry for $\mathrm{Pd}(\mathrm{II})$ is obtained. Then, displacement of one acetate can take place upon which the allylbenzene substrate coordinates in the expected $\eta^{2}$-fashion. Coordination of the alkene increases the Gibbs free energy by $60 \mathrm{~kJ} / \mathrm{mol}$ because the alkene is not as competent a ligand as the acetate ion. However, because this ligand exchange involves molecules of different charge, this comparison is challenging. ${ }^{26}$

Although it can be challenging to distinguish between different $\mathrm{C}-\mathrm{H}$ activation mechanisms experimentally, much insight has already been gained using theoretical methods. ${ }^{2 b}$ This includes the computational studies of the mechanism of cyclometalation in aromatic $\mathrm{C}-\mathrm{H}$ activation by Davies and Macgregor $^{27,28}$ and also studies on the mechanism of palladium-catalyzed intramolecular arylation by Maseras and Echavarren. ${ }^{29}$
On the basis of the results from the Hammett study, the C$\mathrm{H}$ activation step should involve a proton abstraction. However, this proton abstraction can take place through several distinct molecular mechanisms (Scheme 4).

Scheme 4. Five Proposed Proton Abstraction Mechanisms

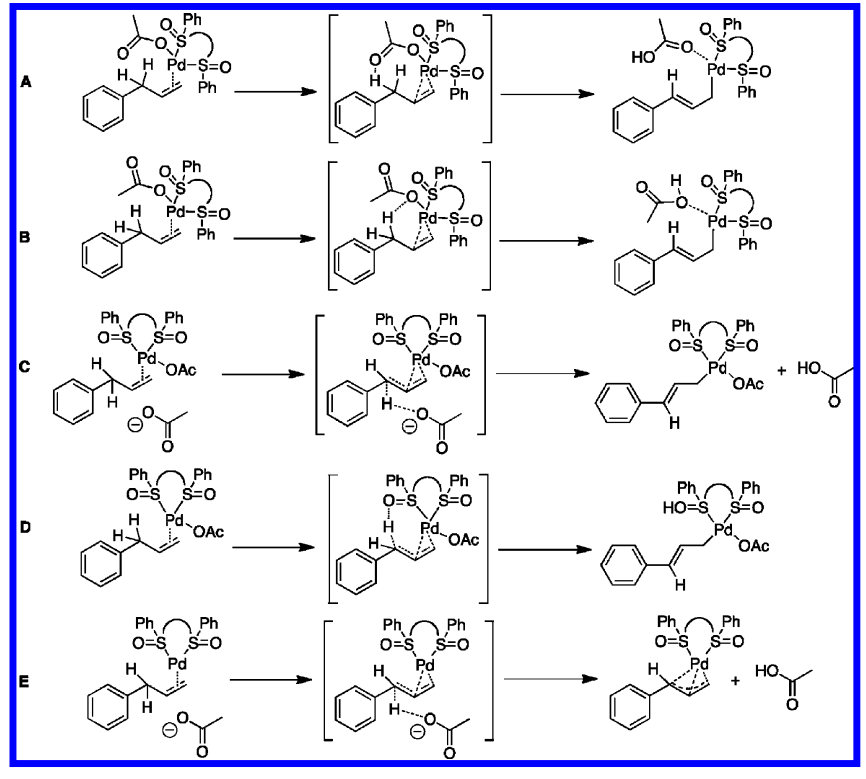

The proton could be abstracted by either the sulfoxide ligand or an acetate anion functioning as an internal or external base. That an acetate anion can act as an internal base to facilitate the cleavage of a $\mathrm{C}-\mathrm{H}$ bond has been reported previously with an iridium catalyst. ${ }^{28,30}$ For allylic $\mathrm{C}-\mathrm{H}$ oxidation, White and coworkers have suggested that a carboxylate counterion on palladium is needed to effect $\mathrm{C}-\mathrm{H}$ cleavage. ${ }^{31}$ A carboxylate anion also plays a key role in the $\mathrm{C}-\mathrm{H}$ activation step of the proposed $\mathrm{Pd}(\mathrm{II}) / \mathrm{Pd}(\mathrm{IV})$ catalytic cycle for an allylic $\mathrm{C}-\mathrm{H}$ acetoxylation $^{32}$ or as a base in a recently published allylic acyloxylation. ${ }^{33}$ Similarly, for allylic aminations, a carboxylate anion has also been suggested to be involved in the cleavage of the $\mathrm{C}-\mathrm{H}$ bond. ${ }^{34,35}$ Indeed, the key role of acetate as an internal or external base has been proposed for several catalytic systems with $\mathrm{Pd}^{36,37}$ Davies and Macgregor have published a computational study evaluating proposed aromatic $\mathrm{C}-\mathrm{H}$ bond activation mechanisms involving palladium acetate. ${ }^{27}$ On the basis of this, we have formulated five different $\mathrm{C}-\mathrm{H}$ activation mechanisms involving a proton abstraction in Scheme 4. Scenarios A, B, C, and E all involve acetate ions; scenarios A and $\mathrm{B}$ have the acetate, which is abstracting the proton, coordinated directly to palladium. These two scenarios resemble two of the mechanisms reported by Davies and Macgregor, in which it was found that a six-membered TS was more favorable than a four-membered. ${ }^{27}$

In addition, we have included two scenarios ( $\mathrm{C}$ and $\mathrm{E}$ ) in which the proton is abstracted by an external acetate ion. In scenario E, there is a vacant coordination site on palladium, which allows for the direct formation of an $\eta^{3}$-coordinated allyl moiety.

However, when calculating energies for the initial allylbenzene complexes in scenarios A and E, scenario A was favored by $123 \mathrm{~kJ} / \mathrm{mol}$. Thus, it can be concluded that scenario E, in which no acetate is coordinated to palladium, is unlikely and can be excluded. 


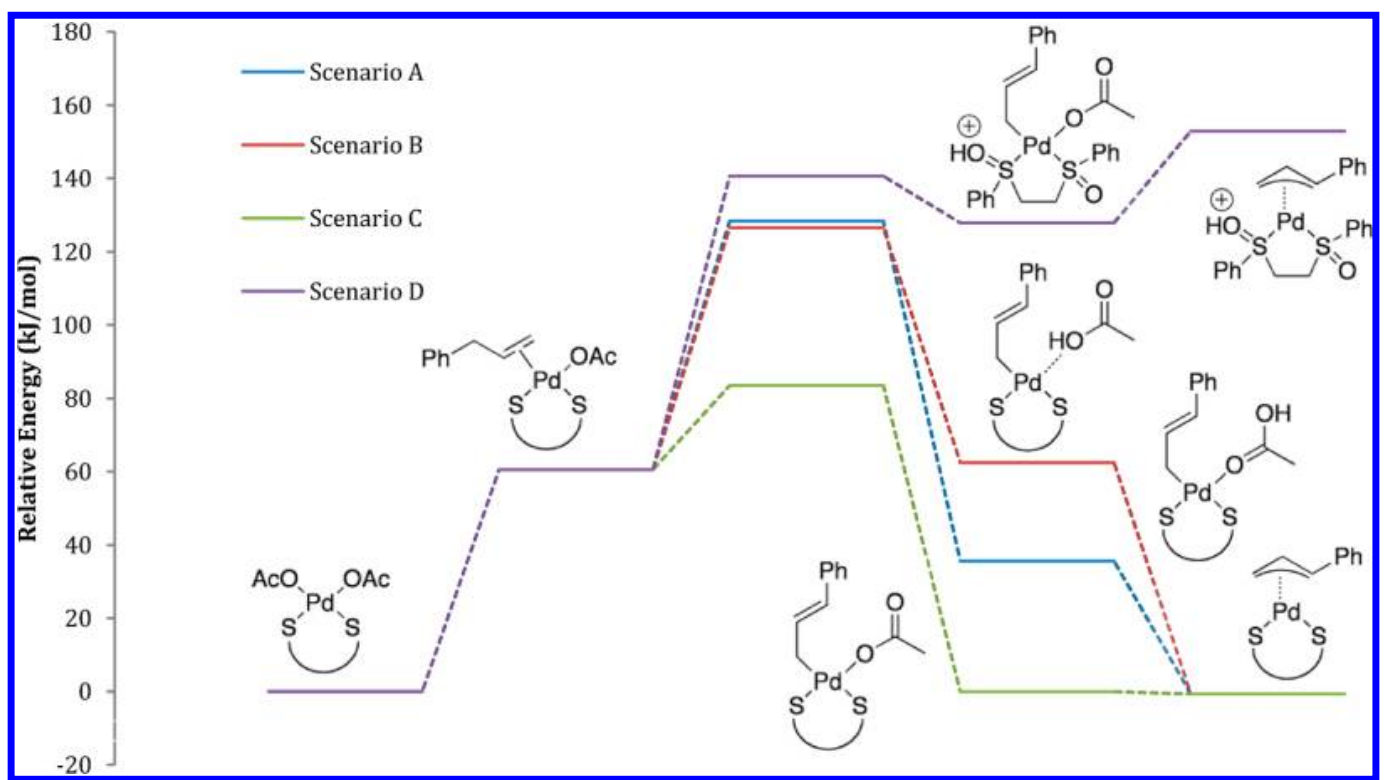

Figure 4. Comparison of the energy profiles for the $\mathbf{C}-\mathbf{H}$ activation mechanisms A-D. Phenyl groups and oxygen atoms on the ligand have been omitted for clarity unless they participate directly in the depicted mechanism.

The Gibbs free energy for the transition states of A, B, C, and $\mathrm{D}$ were determined, and the relative activation energies for the transition states are shown in Figure 4.

The proton abstraction facilitated by the sulfoxide ligand, D (Figure 5), resulted in an activation energy of $80 \mathrm{~kJ} / \mathrm{mol}$,

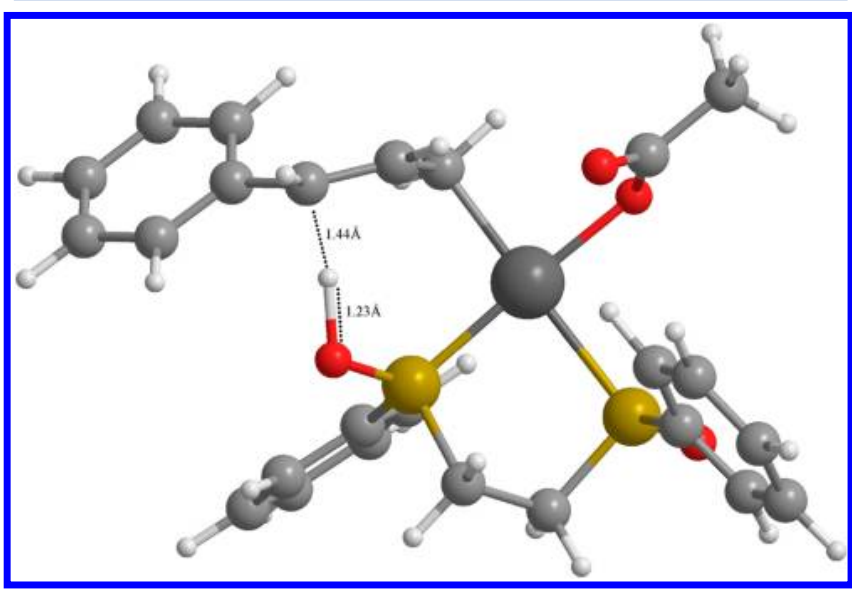

Figure 5. Transition state for the ligand-facilitated abstraction $\mathrm{D}$ of the allylic proton.

making this scenario less favorable than A (Figure 6), which had an activation energy of $68 \mathrm{~kJ} / \mathrm{mol}$. The energy barrier for B (Figure 7) is only $2 \mathrm{~kJ} / \mathrm{mol}$ lower than $\mathrm{A}$, which makes a direct comparison difficult; however, this is in agreement with earlier studies reported by Davies and Macgregor, in which a sixmembered transition state was favored. ${ }^{27}$ For C (Figure 8), a TS with an energy barrier of only $23 \mathrm{~kJ} / \mathrm{mol}$ was found. Although this initially seems to be much more favorable than the other pathways, this result is very difficult to compare directly with A and B because of the added entropic cost of bringing in another acetate ion together with the palladium complex. This cost has previously been estimated as $40 \mathrm{~kJ} /$ $\mathrm{mol}^{38,39}$ which would potentially make $\mathrm{C}$ only $3 \mathrm{~kJ} / \mathrm{mol}$ lower in energy than $\mathrm{B}$.

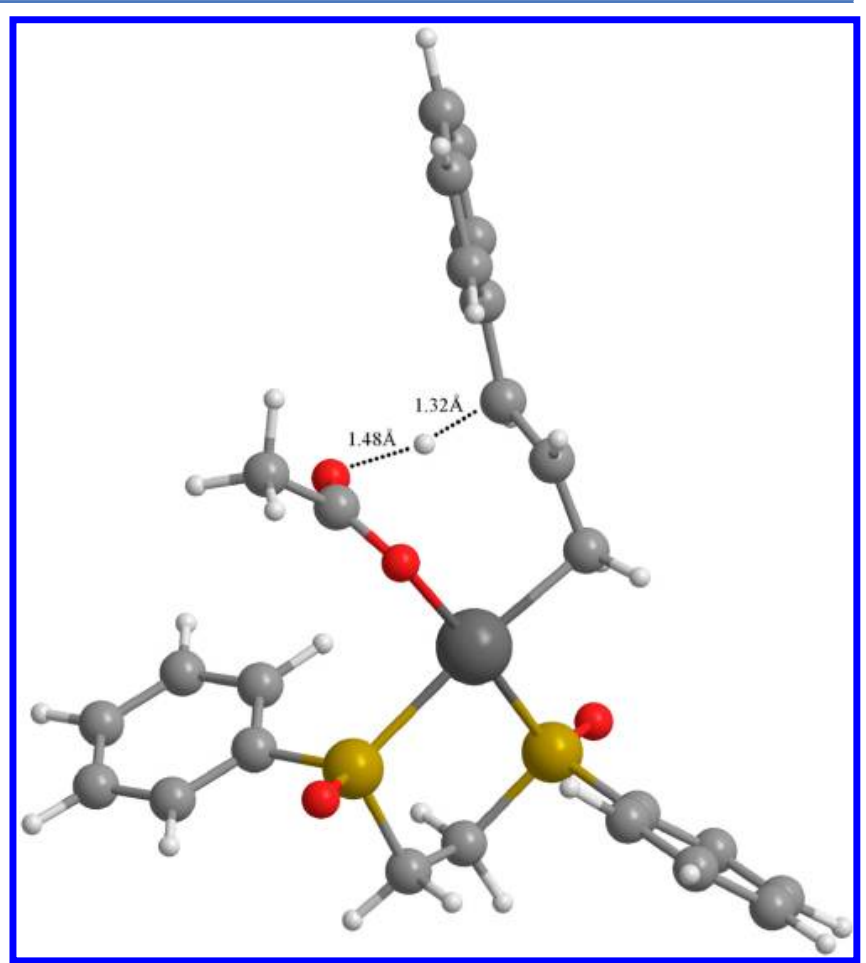

Figure 6. Transition state for the internal acetate abstraction A of the allylic proton.

Having obtained the result that three of the scenarios are very similar in energy (A, B and C), we proceeded to calculate the KIE for each of these pathways. The experimental value obtained for the $\mathrm{C}-\mathrm{H}$ alkylation was 5.5, whereas a calculation of the KIE for A gave a value of 5.3. This is relatively close to the experimental value, but the calculated KIE for B was 5.5, matching the experimental value. It should be noted that breaking the $\mathrm{C}-\mathrm{H}$ bond completely results in a $\mathrm{KIE}$ value of 6.0 at $45{ }^{\circ} \mathrm{C}$. It can be difficult to differentiate between the inter- and intramolecular base-assisted mechanisms, as pointed out by Echavarren and co-workers using DFT calculations. ${ }^{40}$ 


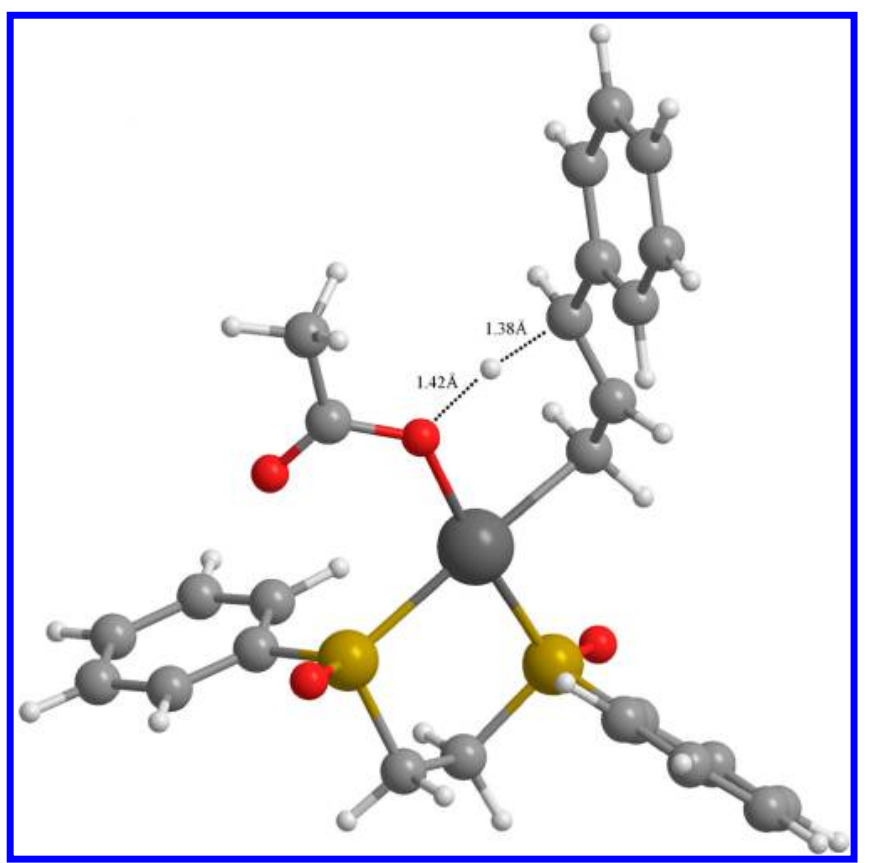

Figure 7. Transition state for the internal acetate abstraction $\mathrm{B}$ of the allylic proton.

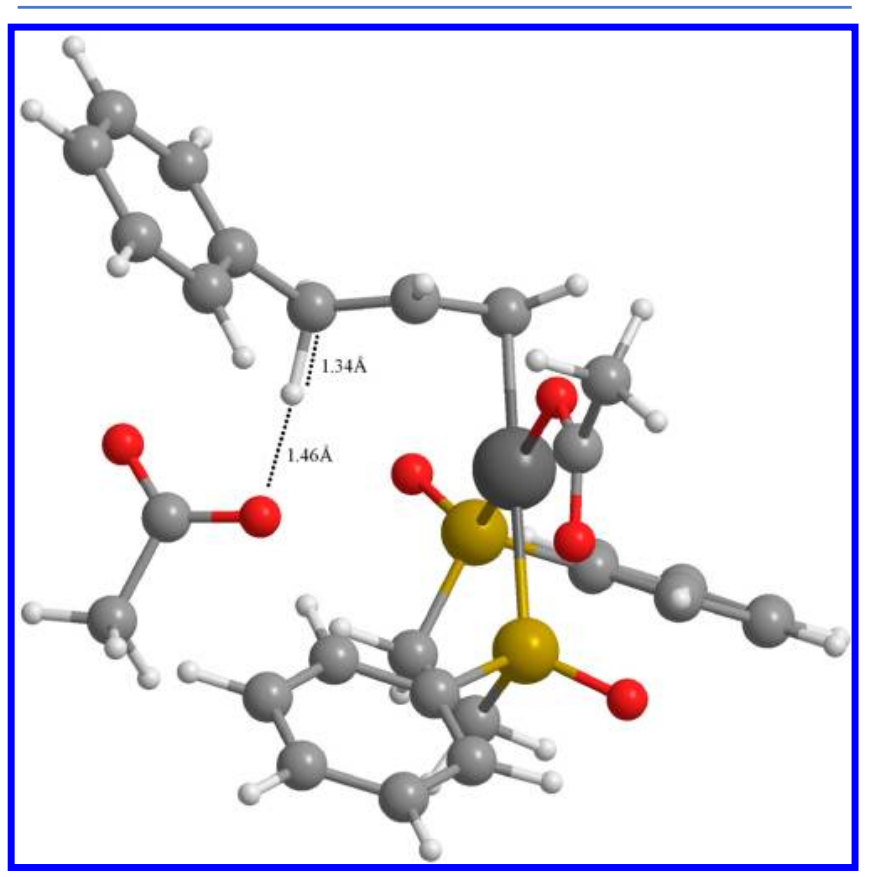

Figure 8. Transition state for the external acetate abstraction $\mathrm{C}$ of the allylic proton.

However, in the current study, the calculated KIE value for C was 5.9, supporting an intramolecular base-assisted mechanism. This value is obtained when utilizing a reference structure for $\mathrm{C}$ in which the external acetate is $1.6 \AA$ from the hydrogen on the substrate. However, the $\mathrm{KIE}$ for $\mathrm{C}$ is very dependent on the choice of reference structure for this particular $\mathrm{C}-\mathrm{H}$ activation mechanism. For example, changing the starting point to a distance of $1.5 \AA$ results in a KIE value of 3.9 (see the Supporting Information). The distance between acetate and hydrogen when a hydrogen-bonding interaction is established prior to the $\mathrm{C}-\mathrm{H}$ activation was $\sim 1.48 \AA$, which indicates a much lower KIE value for $\mathrm{C}$ compared with $\mathrm{A}$ and $\mathrm{B}$.
This trend of a smaller KIE value for $\mathrm{C}$ is in line with the observed experimental $\mathrm{KIE}$ value for the allylic $\mathrm{C}-\mathrm{H}$ acetoxylation. This indicates that $\mathrm{C}$, where the proton is abstracted by an external acetate, is the more dominating $\mathrm{C}-\mathrm{H}$ activation mechanism in that reaction as a result of an excess of acetate present in solution. The experimental KIE value of 4.7 determined for the allylic $\mathrm{C}-\mathrm{H}$ amination is between the two $\mathrm{KIE}$ values calculated for $\mathrm{A}$ and $\mathrm{C}$, even though no $\mathrm{AcOH}$ was added to the reaction. However, in the amination reaction, a base is required, and this can act as an even better external proton abstractor than acetate and thereby lower the KIE value. When taken together, all the experimental results support a C$\mathrm{H}$ activation mechanism in which acetate plays a pivotal role.

Determining the intermediates and transition states for the nucleophilic attack and reoxidation of the catalyst was also done, as is shown in Figure 9.

After the $\mathrm{C}-\mathrm{H}$ activation, the $\mathrm{Pd}$ catalyst is coordinated to $\mathrm{AcOH}$ and the formed allyl moiety in an $\eta^{1}$-coordinated fashion. A total of $35 \mathrm{~kJ} / \mathrm{mol}$ is gained by forming the $\eta^{3}$ coordinated allyl-Pd complex in the next step. From here, a prereactive state for the nucleophilic attack can be defined, which increases the energy by $19 \mathrm{~kJ} / \mathrm{mol}$. The nucleophile can approach the allyl from various angles and with different conformations, and the formation of both a linear and a branched product is possible;however, calculations showed a favorable reaction path in which the nucleophile attacks from the opposite side of the coordinated Pd with a certain conformation (see the Supporting Information). Since the linear product is the dominating product from the reaction, this structure is utilized in the overall energy diagram. Comparing the average energy barriers for the possible nucleophilic attacks leading to the linear and the branched product gives a product ratio of $7.8: 1$, fairly close to the experimental ratio of $4: 1 .^{4}$ The formation of the product and the reduction of $\operatorname{Pd}(\mathrm{II})$ to $\operatorname{Pd}(0)$ makes the overall energy of the system drop significantly.

The reoxidation of the catalyst has previously been investigated on a simplified system with DFT calculations by Poli and co-workers. ${ }^{41}$ Utilizing these results but employing the full ligand for the catalyst gave a reoxidation pathway with energy barriers similar to those reported by Poli and coworkers, as expected. During the reoxidation, two hydrogen atoms are transferred from $\mathrm{AcOH}$ molecules to quinone, which is reduced to hydroquinone, and $\mathrm{Pd}$ is oxidized to regenerate the catalyst.

Using the AUTOF program developed by Shaik and Kozuch, the KIE for the whole catalytic cycle could be calculated from the TOF of the Pd-catalyzed allylic $\mathrm{C}-\mathrm{H}$ alkylation. ${ }^{42}$ This gave a KIE value of 4.1 , which is not close to the 2.6 observed experimentally, but this value value is very dependent on small energy differences between the two dominating TS in the catalytic cycle. The fact that the value is smaller than the KIE determined on the $\mathrm{C}-\mathrm{H}$ activation TS alone implies that the TS with the maximum energy in the reoxidation step has an impact on the overall reaction rate of the reaction.

The electronic properties induced by the sulfoxide ligand on the palladium complex makes the benzylic/allylic $\mathrm{C}-\mathrm{H}$ bond more prone to cleavage. The calculated charges of the various carbon atoms in the allylbenzene substrate as it coordinates to 1 shows that charge from the benzylic/allylic position is being distributed into the coordinated olefin and into the aromatic system (see the Supporting Information). This lowers the $\mathrm{p} K_{\mathrm{a}}$ value of the benzylic protons, and $\mathrm{C}-\mathrm{H}$ bond cleavage becomes much more facile. When the allyl-complex is formed, the 


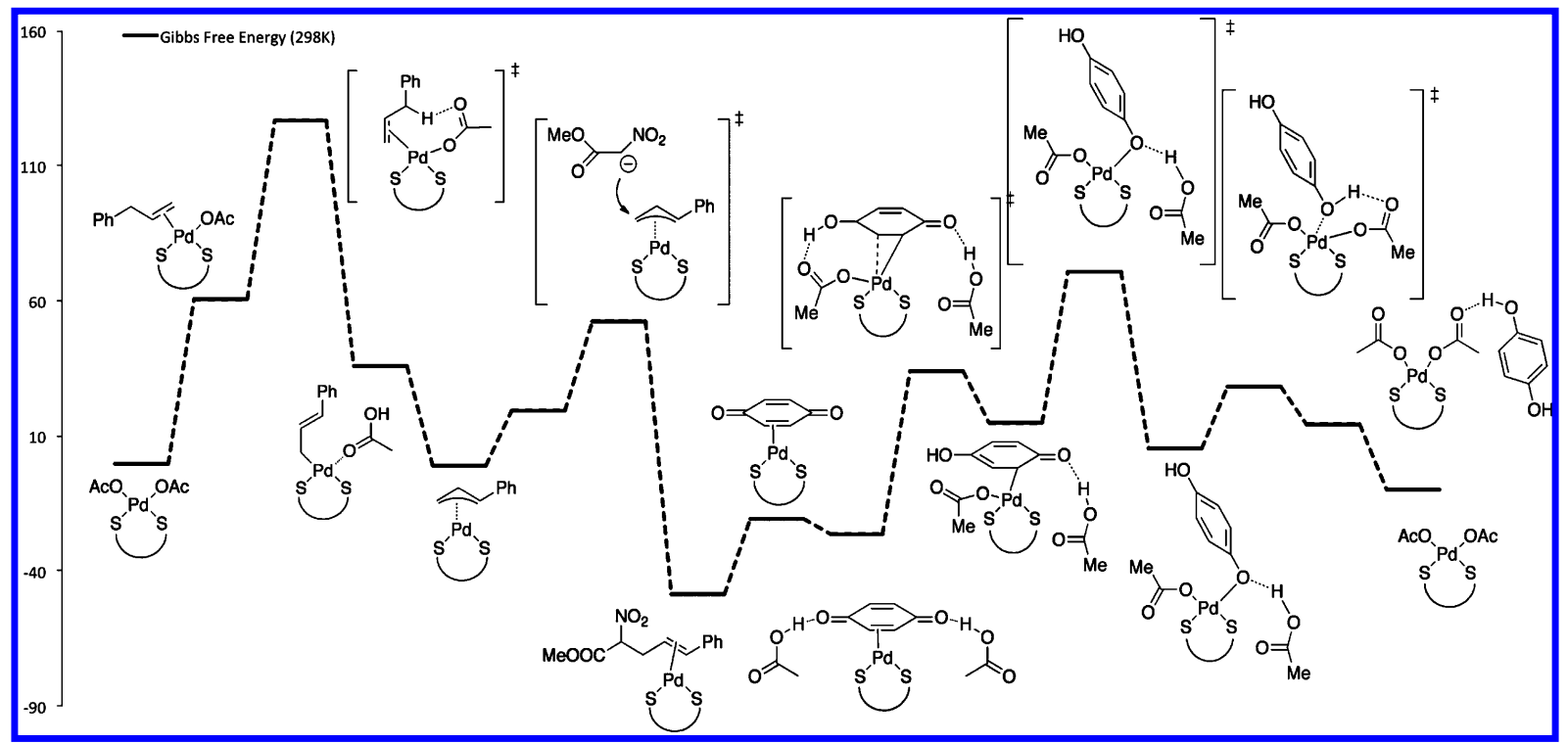

Figure 9. The energy diagram for a full catalytic cycle, with $\mathrm{C}-\mathrm{H}$ activation $\mathrm{A}$ (the ligand is simplified, so oxygen and phenyl substituents are not shown).

benzylic carbon regains some charge, while the other carbons in the substrate decrease their charge slightly.

\section{CONCLUSIONS}

The mechanism for the palladium-catalyzed allylic $\mathrm{C}-\mathrm{H}$ activation has been investigated with a Hammett study, kinetic isotope effect determination, and density functional theory calculations. The Hammett study shows buildup of a partial negative charge in the rate-determining step, supporting a proton abstraction mechanism. Determining the KIE values for the palladium-catalyzed allylic $\mathrm{C}-\mathrm{H}$ alkylation, acetoxylation, and amination further establishes that the $\mathrm{C}-\mathrm{H}$ activation step is the rate-determining step in these reactions. Using DFT calculations, the various possible $\mathrm{C}-\mathrm{H}$ activation mechanisms were investigated, and transition states for these mechanisms were determined. Calculating theoretical KIE values from these transition states showed good agreement with experimental KIE values and allowed discrimination between different plausible mechanistic scenarios. The comparison between experimental and theoretical $\mathrm{KIE}$ values supports a $\mathrm{C}-\mathrm{H}$ activation mechanism in which acetate plays a pivotal role as an either internal or external proton abstractor. This insight into the allylic $\mathrm{C}-\mathrm{H}$ activation mechanism paves the way for further improvement and expansion of this important methodology, and the good correspondence between experimental and theoretical results should allow for rational design of future $\mathrm{C}-\mathrm{H}$ activation catalysts.

\section{EXPERIMENTAL DETAILS}

Glassware was dried in an oven at $140{ }^{\circ} \mathrm{C}$. All solvents were purchased from Sigma-Aldrich (HPLC grade) and were used as received. Dodecane, $\mathrm{Pd}[1,2$-bis(phenylsulfonyl)ethane $]$ $(\mathrm{OAc})_{2}$, 2,6-dimethylbenzoquinone, 4-allyltoluene, and 1-allyl4-methoxybenzene were purchased from Sigma-Aldrich and were used without further purification. Allylbenzene and methyl nitroacetate were distilled before use. GC/MS analysis was performed on a Shimadzu QP5000 GC/MS instrument using electron impact as the ionization method and a $30 \mathrm{~m} \times 0.25$ $\mathrm{mm} \times 0.25 \mu \mathrm{m}$ Supelco Equity-1 capillary column. For the Hammett study experiments, procedure A was used: oven temperature started at $60^{\circ} \mathrm{C}$ for $5 \mathrm{~min}$, followed by a ramp $(20$ ${ }^{\circ} \mathrm{C} / \mathrm{min}$ ) to $250{ }^{\circ} \mathrm{C}$ which was kept for $6 \mathrm{~min}$. For KIE experiments, procedure $\mathrm{B}$ was used: oven temperature started at $60{ }^{\circ} \mathrm{C}$ for $5 \mathrm{~min}$, followed by a ramp $\left(10^{\circ} \mathrm{C} / \mathrm{min}\right)$ to $300^{\circ} \mathrm{C}$, which was kept for $5 \mathrm{~min}$. For deuterium scrambling experiments, procedure $\mathrm{C}$ was used: oven temperature started at $60{ }^{\circ} \mathrm{C}$ for $5 \mathrm{~min}$, followed by a $\operatorname{ramp}\left(12{ }^{\circ} \mathrm{C} / \mathrm{min}\right)$ to $280{ }^{\circ} \mathrm{C}$, which was kept for $2 \mathrm{~min}$.

General Procedure for Hammett Study. To a screw cap vial, $\mathrm{Pd}[1,2$-bis(phenylsulfonyl)ethane $](\mathrm{OAc})_{2}(0.05 \mathrm{mmol}, 25$ $\mathrm{mg}), 2,6$-dimethylbenzoquinone $(0.75 \mathrm{mmol}, 102 \mathrm{mg})$, and a stir bar were added. Allylbenzene $(0.25 \mathrm{mmol}, 30 \mathrm{mg})$, parasubstituted allylbenzene $(0.25 \mathrm{mmol})$ under investigation, methyl nitroacetate $(1.5 \mathrm{mmol}, 178 \mathrm{mg})$, AcOH $(0.25 \mathrm{mmol}$, $15 \mathrm{mg}$ ), and dodecane as internal standard (0.125 mmol, 21 $\mathrm{mg}$ ) were weighed out in a $1.0 \mathrm{~mL}$ vial and transferred to the catalyst mixture using dioxane/dimethyl sulfoxide (DMSO) $(4: 1)(1.5 \mathrm{~mL})$. The reaction was sealed with a screw cap fitted with a PTFE septum and placed in an aluminum block preheated to $45^{\circ} \mathrm{C}$. Samples of $0.05 \mathrm{~mL}$ each were withdrawn from the reaction mixture after $0,0.5,1,2,4,6,8$, and $24 \mathrm{~h}$ reaction time, diluted with diethylether $(1 \mathrm{~mL})$ and analyzed by GC/MS.

General Procedure for KIE Experiments. To a screw-cap vial was added $\mathrm{Pd}[1,2$-bis(phenylsulfonyl)ethane $](\mathrm{OAc})_{2}(0.05$ mmol, $25 \mathrm{mg}$ ), 2,6-dimethylbenzoquinone (1 mmol, $136 \mathrm{mg}$ ) as oxidant, and a stir bar. Allylbenzene $(0.25 \mathrm{mmol}, 30 \mathrm{mg}), d_{2^{-}}$ allylbenzene $(0.25 \mathrm{mmol}, 30 \mathrm{mg})$, nucleophile, and dodecane as internal standard $(0.125 \mathrm{mmol}, 21 \mathrm{mg})$ were weighed out in a $1.0 \mathrm{~mL}$ vial and transferred to the catalyst mixture. The reaction was sealed with a screw cap fitted with a PTFE septum and placed in an aluminum block preheated to $45{ }^{\circ} \mathrm{C}$. Samples of $0.05 \mathrm{~mL}$ each were withdrawn from the reaction mixture during the reaction time, diluted with diethylether $(1 \mathrm{~mL})$ and analyzed by GC/MS.

General Procedure for Deuterium Scrambling Experiments. To a screw-cap vial was added Pd[1,2-bis(phenylsulfonyl)ethane]-(OAc) 2 (0.05 mmol, $25 \mathrm{mg}), 2,6-$ dimethylbenzoquinone ( $1 \mathrm{mmol}, 136 \mathrm{mg}$ ) as oxidant, and a stir bar. 4-Allyltoluene $(0.25 \mathrm{mmol}, 33 \mathrm{mg}), d_{2}$-allylbenzene $(0.25$ 
mmol, $30 \mathrm{mg}$ ), nucleophile, and dodecane as internal standard $(0.125 \mathrm{mmol}, 21 \mathrm{mg})$ were weighed out in a $1.0 \mathrm{~mL}$ vial and transferred to the catalyst mixture. The reaction was sealed with a screw cap fitted with a PTFE septum and placed in an aluminum block preheated to $45{ }^{\circ} \mathrm{C}$. Samples of $0.05 \mathrm{~mL}$ each were withdrawn from the reaction mixture during the reaction time, diluted with diethylether $(1 \mathrm{~mL})$ and analyzed by GC/ MS.

For the allylic $\mathrm{C}-\mathrm{H}$ alkylation reactions, methyl nitroacetate (1.5 mmol, $178 \mathrm{mg})$, 2,6-dimethylbenzoquinone $(0.75 \mathrm{mmol}$, $102 \mathrm{mg})$, and $\mathrm{AcOH}(0.25 \mathrm{mmol}, 15 \mathrm{mg})$ were added to dioxane/DMSO (4:1) $(1.5 \mathrm{~mL})$. Samples were taken from the reaction mixture after $0,0.5,1,2,4,6,8$, and $24 \mathrm{~h}$ reaction time.

For the allylic $\mathrm{C}-\mathrm{H}$ acetoxylation reactions, 2,6-dimethylbenzoquinone ( $1.0 \mathrm{mmol}, 136 \mathrm{mg}$ ) wass added in $\mathrm{CH}_{2} \mathrm{Cl}_{2} /$ $\mathrm{AcOH}(3 \mathrm{~mL})$. Samples were taken from the reaction mixture after $0,1,3,6,24,28,32$, and 48 h reaction time.

For the allylic $\mathrm{C}-\mathrm{H}$ amination reactions, methyl tosylcarbamate (1.0 mmol, $229 \mathrm{mg}$ ), 2,6-dimethylbenzoquinone (1.0 mmol, $136 \mathrm{mg})$, and $\mathrm{Et}_{3} \mathrm{~N}(0.03 \mathrm{mmol}, 4 \mu \mathrm{L})$ were added to tert-butyl methyl ether $(1.2 \mathrm{~mL})$. Samples were taken from the reaction mixture after $0,0.5,1,2,3,4,6$, and $8 \mathrm{~h}$ reaction time.

\section{COMPUTATIONAL DETAILS}

Visualization and comparison of structures were performed in Maestro version 9.1.107. ${ }^{43}$ DFT calculations were performed with the B3LYP functional with added D3 corrections ${ }^{21}$ (and all important structures, intermediates and transition states were also determined with the M06 functional for comparison $^{44}$ ) employing the LACVP* basis set, which uses the HayWadt ECP and basis set for palladium, and the 6-31G* basis set for all other atoms. ${ }^{23,24}$ In the gas phase, intermediates and transition states were characterized by a full, analytic frequency calculation, which resulted in only positive frequencies for intermediates and exactly one imaginary frequency for transition states. Approximate Gibbs free energies in the solution phase $\left(\Delta G_{\text {solv }}\right)$ were obtained by combining the solution-phase energies $\left(\Delta E_{\text {solv }}\right)$ with the vibrational contribution from the gas phase $\left(\Delta G_{\text {gas }}-\Delta E_{\text {gas }}\right)$ in line with earlier work $\left(\Delta G_{\text {solv }}=\Delta E_{\text {solv }}+\Delta G_{\text {gas }}-\Delta E_{\text {gas }}\right) .10 a$

A theoretical estimation of the kinetic isotope effect was performed using the available Hessian from the full frequency calculation by simply changing the isotope of the one benzylic/ allylic $\mathrm{H}$ atom prone for abstraction. To allow comparison with the experimental value, approximate Gibbs free energies in the solution phase (composite energy) were calculated for a temperature of $318 \mathrm{~K}$.

\section{ASSOCIATED CONTENT}

\section{S Supporting Information}

Detailed experimental procedures, additional kinetic plots along with XYZ coordinates, SCF energies, and Gibbs free energies ( 298 and $318 \mathrm{~K}$ ) for all structures with the full experimental ligand. This material is available free of charge via the Internet at http://pubs.acs.org

\section{AUTHOR INFORMATION}

\section{Corresponding Author}

*E-mail: pf@kemi.dtu.dk.

\section{Present Addresses}

${ }^{\dagger}$ Lundbeck Pharma A/S, Ottiliavej 9, 2500 Valby, Denmark.
† Procter \& Gamble, Temselaan 55,B-1853, Strombeek-Bever, Belgium

Notes

The authors declare no competing financial interest.

\section{ACKNOWLEDGMENTS}

We are grateful for financial support from the Danish Council for Independent Research, Grant no. 11-105487 and the Technical University of Denmark.

\section{REFERENCES}

(1) The synthesis of Brevetoxin B is an example of this: Nicolaou, K. C.; Rutjes, F. P. J. T.; Theodorakis, E. A.; Tiebes, J.; Sato, M.; Untersteller, E. J. Am. Chem. Soc. 1995, 117, 10252-10263.

(2) Volume 110, Issue 2, of the journal Chemical Reviews provides review articles on the topic of $\mathrm{C}-\mathrm{H}$ bond activation and functionalization. For example, see: (a) Crabtree, R. H. Chem. Rev. 2010, 110, 575-624. (b) Shilov, A. E.; Shul'pin, G. B. Chem. Rev. 1997, 97, 2879-2932. For a review on computational $\mathrm{C}-\mathrm{H}$ activation, see: (c) Balcells, D.; Clot, E.; Eisenstein, O. Chem. Rev. 2010, 110, 749-823.

(3) (a) Neufeldt, S. R.; Sanford, M. S. Acc. Chem. Res. 2012, 45, 936946. (b) Sigman, M. S.; Werner, E. W. Acc. Chem. Res. 2012, 45, 874884. (c) Campbell, A. N.; Stahl, S. S. Acc. Chem. Res. 2012, 45, 851863. (d) Engle, K. M.; Mei, T.-S.; Wasa, M.; Yu, J.-Q. Acc. Chem. Res. 2012, 45, 788-802. (e) Chen, X.; Engle, K. M.; Wang, D.-H.; Yu, J.-Q. Angew. Chem., Int. Ed. 2009, 48, 5094-5115. (f) Jensen, T.; Fristrup, P. Chem.-Eur. J. 2009, 38, 9632-9640. (g) Engelin, C. J.; Fristrup, P. Molecules 2011, 16, 951-969.

(4) Young, A. J.; White, M. C. J. Am. Chem. Soc. 2008, 130, 1409014091.

(5) Lin, S.; Song, C.-X.; Cai, G.-X.; Wang, W.-H.; Shi, Z.-J. J. Am. Chem. Soc. 2008, 130, 12901-12903.

(6) For reviews of the Tsuji-Trost reaction, see: (a) Tsuji, J. Palladium Reagents and Catalysts: New Perspectives for the 21st Century; John Wiley \& Sons, Ltd.: Chichester, U.K., 2004; chapter 4. (b) Trost, B. M.; Crawley, M. L. Chem. Rev. 2003, 103, 2921-2943. (c) Trost., B. M. J. Org. Chem. 2004, 69, 5813-5837. (d) Handbook of Organopalladium Chemistry for Organic Synthesis Negishi, E.-I., Ed.; Wiley-Interscience; New York, 2002.

(7) Trost, B. M.; Fullerton, T. J. J. Am. Chem. Soc. 1973, 95, 292294

(8) (a) Covell, D. J.; White, C. W. Angew. Chem., Int. Ed. 2008, 47, 6448-6451. (b) Chai, Z.; Rainey, T. J. J. Am. Chem. Soc. 2012, 134, $3615-3618$.

(9) (a) Makarov, I. S.; Fristrup, P.; Madsen, R. Chem.-Eur. J. 2012, 18, 15683-15692. (b) Fristrup, P.; Tursky, M.; Madsen, R. Org. Biomol. Chem. 2012, 10, 2569-2577. (c) Fristrup, P.; Kreis, M.; Palmelund, A.; Norrby, P.-O.; Madsen, R. J. Am. Chem. Soc. 2008, 130, 5206-5215.

(10) (a) Keinicke, L.; Fristrup, P.; Norrby, P.-O.; Madsen, R. J. Am. Chem. Soc. 2005, 127, 15756-15761. (b) Fristrup, P.; Le Quement, S.; Tanner, D.; Norrby, P.-O. Organometallics 2004, 23, 6160-6165.

(11) Fristrup, P.; Jensen, G. H.; Andersen, M. L. N.; Tanner, D.; Norrby, P.-O. J. Organomet. Chem. 2006, 691, 2182-2198.

(12) Fristrup, P.; Tanner, D.; Norrby, P.-O. Chirality 2003, 15, 360368.

(13) White and coworkers have recently shown that unactivated olefins can also undergo allylic $\mathrm{C}-\mathrm{H}$ activation. See: Young, A. J.; White, M. C. Angew. Chem., Int. Ed. 2011, 50, 6824-6827.

(14) Hansch, C.; Leo, A.; Taft, R. W. Chem. Rev. 1991, 91, 165-195.

(15) (a) Fristrup, P.; Johansen, L. B.; Christensen, C. H. Catal. Lett. 2008, 140, 184-190. (b) Fristrup, P.; Johansen, L. B.; Christensen, C. H. Chem. Commun. 2008, 24, 2750-2752.

(16) The reported catalyst for the $\mathrm{C}-\mathrm{H}$ acetoxylation uses benzyl groups instead of phenyl groups on the bisulfoxide ligand; however, in 
this study, $\mathbf{1}$ is used to allow a direct comparison among the three transformations.

(17) Reed, S. A.; Mazzotti, A. R.; White, M. C. J. Am. Chem. Soc.

2009, 131, 11701-11706.

(18) Chen, M. S.; White, M. C. J. Am. Chem. Soc. 2004, 126, 13461347.

(19) Gómez-Gallego, M.; Sierra, M. A. Chem. Rev. 2011, 111, 48574963.

(20) Simmons, E. M.; Hartwig, J. F. Angew. Chem., Int. Ed. 2012, 51, 3066-3072.

(21) Grimme, S.; Antony, J.; Ehrlich, S.; Krieg, H. J. Chem. Phys. 2010, 132, 154104.

(22) Bantreil, X.; Prestat, G.; Moreno, A.; Madec, D.; Fristrup, P.; Norrby, P.-O.; Pregosin, P. S.; Poli, G. Chem.-Eur. J. 2011, 17, 28852896.

(23) (a) Becke, A. D. J. Chem. Phys. 1993, 98, 5648-5652. (b) Becke, A. D. J. Chem. Phys. 1993, 98, 1372-1377. (c) Lee, C.; Yang, W.; Parr, R. G. Phys. Rev. B 1988, 37, 785-789.

(24) LACVP* uses the 6-31G* basis set for all light elements and the Hay-Wadt ECP and basis set for palladium; see: Hay, P. J.; Wadt, W. R. J. Chem. Phys. 1985, 82, 299-310.

(25) Commercially available catalyst $\mathbf{1}$ and synthesized catalyst from meso ligand were used interchangeably by White with no significant variations observed.

(26) For a discussion of this in the context of chloride ions in the Tsuji-Trost alkylation, see: Fristrup, P.; Ahlquist, M.; Tanner, D.; Norrby, P.-O. J. Phys. Chem. A. 2008, 112, 12862-12867.

(27) Davies, D. L.; Donald, S. M. A.; Macgregor, S. A. J. Am. Chem. Soc. 2005, 127, 13754-13755.

(28) Davies, D. L.; Donald, S. M. A.; Al-Duaij, O.; Fawcett, J.; Little, C.; Macgregor, S. A. Organometallics 2006, 25, 5976-5978.

(29) García-Cuadrado, D.; Braga, A. A. C.; Maseras, F.; Echavarren, A. M. J. Am. Chem. Soc. 2006, 128, 1066-1067.

(30) Boutadla, Y.; Al-Duaij, O.; Davies, D. L.; Griffith, G. A.; Singh, K. Organometallics 2009, 28, 433-440.

(31) Vermeulen, N. A.; Delcamp, J. H.; White, M. C. J. Am. Chem. Soc. 2010, 132, 11323-11328.

(32) Pilarski, L. T.; Selander, N.; Böse, D.; Szabó, K. J. Org. Lett. 2009, 11, 5518-5521.

(33) Thiery, E.; Aouf, C.; Belloy, J.; Harakat, D.; Le Bras, J.; Muzart, J. J. Org. Chem. 2010, 75, 1771-1774.

(34) Shimizu, Y.; Obora, Y.; Ishii, Y. Org. Lett. 2010, 12, 1372-1374.

(35) Reed, S. A.; Mazzotti, A. R.; White, M. C. J. Am. Chem. Soc. 2009, 131, 11701-11706.

(36) Lapointe, D.; Fagnou, K. Chem. Lett. 2010, 39, 1118-1126.

(37) Boutadla, Y.; Davies, D. L.; Macgregor, S. A.; PobladorBahamonde, A. I. Dalton Trans. 2009, 5820-5831.

(38) Searle, M. S.; Westwell, M. S.; Williams, D. H. J. Chem. Soc., Perkin Trans. 2 1995, 1, 141-151.

(39) Seth, M.; Senn, H. M.; Ziegler, T. J. Phys. Chem. A 2005, 109, $5136-5143$.

(40) Carcía-Cuadrado, D.; de Mendoza, P.; Braga, A. A. C.; Maseras, F.; Echavarren, A. M. J. Am. Chem. Soc. 2007, 129, 6880-6886.

(41) Nahra, F.; Liron, F.; Prestat, G.; Mealli, C.; Messaoudi, A.; Poli, G. Chem.-Eur. J. 2009, 15, 11078-11082.

(42) (a) Kozuch, S.; Shaik, S. J. Am. Chem. Soc. 2006, 128, 33553365. (b) Kozuch, S.; Shaik, S. J. Phys. Chem. A 2008, 112, 60326041. (c) Uhe, A.; Kozuch, S.; Shaik, S. J. Comput. Chem. 2010, 32, 978-985.

(43) For updated versions, see: www.schrodinger.com (accessed January 22, 2013).

(44) (a) Zhao, Y.; Truhlar, D. G. Theor. Chem. Acc. 2008, 120, 215241. (b) Zhao, Y.; Truhlar, D. G. Acc. Chem. Res. 2008, 41, 157-167. (c) Averkiev, B. B.; Zha, Y.; Truhlar, D. G. J. Mol. Catal. A: Chem. 2010, 324, 80-88. 